\title{
Fabrication of Micro Channel Heat Sink by using Photo Chemical Machining
}

\author{
Mayuri A. Raut, Snehal S. Kale, Prajakta V. Pangavkar, Samadhan J. Shinde, Sandeep S. \\ Wangikar, Subhash V. Jadhav, Digambar T. Kashid
}

\begin{abstract}
Generally Heat Sink is the inactive warmth exchanger that exchanges the warmth produced by an electronic or a mechanical gadget to a liquid medium, for example, air or a fluid coolant, where it is dispersed far from the gadget, along these lines permitting guideline of the gadget's temperature at ideal dimension. In short it is a gadget or a substance for engrossing over the top or undesirable warmth. For the most part heat sinks are accessible at Mouser Electronics. There are different techniques for manufacture of heat sink. Contingent upon their shapes and materials, heat sinks can be made by many assembling strategies. The most widely recognized and financially savvy strategy incorporate expulsion, manufacturing, throwing and stepping. Other greater expense strategies incorporate $\mathrm{CNC}$ machining, skiving and swaging. In this paper, an endeavor has been made for the manufacture of heat sink by utilizing Photo Chemical Machining process. The channels of the heat sinkare made by utilizing photochemical machining process. For this, Ferric Chloride is utilized as the etchant. Further, portrayal is done and after that surface unpleasantness is estimated. From study, we reasoned that the photochemical machining is additionally appropriate for the creation of the heat sink.
\end{abstract}

Index Terms-Micro Channel, Heat Sink, Photo Chemical Machining.

\section{INTRODUCTION}

\subsection{Heat Sink}

Each electrical and electronic part in a circuit produces some measure of warmth while the circuit is executed by giving force supply. Normally high-control semiconducting gadgets like power transistors and the hardware, for example, light transmitting diodes, lasers create heat in impressive sums and these segments are lacking to disseminate heat, as their dispersal ability is fundamentally low. Because of this, warming up of the parts prompts untimely disappointment

Mayuri A. Raut, UG Student, Mechanical Engineering Department, SVERI's College of Engineering, Pandharpur, Maharashtra, India

Snehal S. Kale, UG Student, Mechanical Engineering Department, SVERI's College of Engineering, Pandharpur, Maharashtra, India

Prajakta V. Pangavkar, UG Student, Mechanical Engineering Department, SVERI's College of Engineering, Pandharpur, Maharashtra, India

Samadhan J. Shinde, Assistant Professor, Mechanical Engineering Department, SVERI's College of Engineering, Pandharpur, Maharashtra, India

Sandeep S. Wangikar, Associate Professor, Mechanical Engineering Department, SVERI's College of Engineering, Pandharpur, Maharashtra, India

Subhash V. Jadhav, Assistant Prfoessor, Mechanical Engineering Department, SVERI's College of Engineering, Pandharpur, Maharashtra, India

Digambar T. Kashid, Assistant Professor, Mechanical Engineering Department, SVERI's College of Engineering, Pandharpur, Maharashtra, India and may cause disappointment of the whole circuit or framework's execution.So, to overcome these negative angles, heat sinks must be accommodated cooling reason.

Heat Sink is an electronic part or gadget of an electronic circuit which scatters heat from different segments (primarily from the power transistors) of a circuit into the encompassing medium and cools them for improving the execution, unwavering quality and furthermore maintains a strategic distance from the untimely disappointment of segments. For the cooling reason, it fuses a fan or cooling gadget [1-5].

\subsection{Fabrication Methods}

There are different ways for the assembling of the heat sink. The most widely recognized methods for assembling of air-cooling heat sinks are as per the following:

1. Expulsion

2. Stepping

3. Kick the bucket throwing

4. Holding

5. Collapsing

6. Manufacturing

7. Skiving

8. Machining

Aside from these techniques, heat sink can be fabricated with the assistance of photograph synthetic machining process.

\subsection{Photo Chemical Machining}

The stringent dimensional prerequisites with high surface completion and complex shapes can't be cultivated machining forms. The hard materials are likewise imperatives for the customary machining forms. Besides, the contention in temperature and remaining burdens produced in work piece in view of the ordinary machining procedures may conceivably not be passable for different application. Accordingly, presently a day, non-ordinary machining forms are regularly utilized for assembling of a wide assortment of parts. It incorporates Electrical Discharge Machining (EDM), Laser Machining, Photochemical Machining (PCM), and so on. The PCM procedure depends on the amalgamation of photoresist imaging and substance carving. Photochemical Machining process is an exactness molding of metal into any shape, measure or from without utilizing of physical power, by a controlled concoction activity. Material carved by minuscule electrochemical cell activity, as happens in substance disintegration. Troublesome slight 2D level metal parts are created which are free from pressure and burr with ease and less conveyance time separated from different preferences. It is one of the substance machining process in 
which the photographic and concoction drawing methods are utilized.

The performance of photochemical machining process for different materials like copper, brass, german silver are reported by various researchers [5-10]. The scope of PCM process for fabrication of microdevices like microchannels is discussed by some researchers. [11-13].

\subsection{PCM for manufacture of heat sink of various material}

The heat sinks are manufactured by utilizing photochemical machining process. In which the channels of the heat sink are set up by this procedure. The measure of material is expelled to frame the channels of the heat sink. In this paper, the materials utilized for the creation of the heat sink are copper and aluminum.

\section{MATERIAL SELECTION}

The copper and aluminum material are utilized for this examination.

1. Copper

Copper is pliable and pliant and esteemed for its high warm and electric conductivity. As we are utilizing the heat sink for warmth trade or warmth ingestion, copper is best appropriate for assembling of heat sink as it have all properties required for the heat sink.

\section{Aluminum}

Aluminum has opposition against different types of erosion. Aluminum has great warm and electrical properties. So it is likewise best reasonable for the assembling of heat sink.

\section{EXPERIMENTATION}

The example surface is made clean to evacuate the burr, oxide layer, dust, and so on. In this way, the photoresist can undoubtedly hold fast to the surface.The PCM setup is appeared in Figure 1. The cleaning of the surface is completed by clean paper and more slender (trichloroethylene or $\mathrm{CH} 3$ )2CO) to evacuate hints of oil or oil. In the wake of cleaning the example was plunged out inthe photoresist and dried it to get a layer of photoresist on the outside of the example. A photograph instrument is a negative film of the picture which is should have been delivered, and it is created by utilizing the CAD drawing imprinted on the following paper.

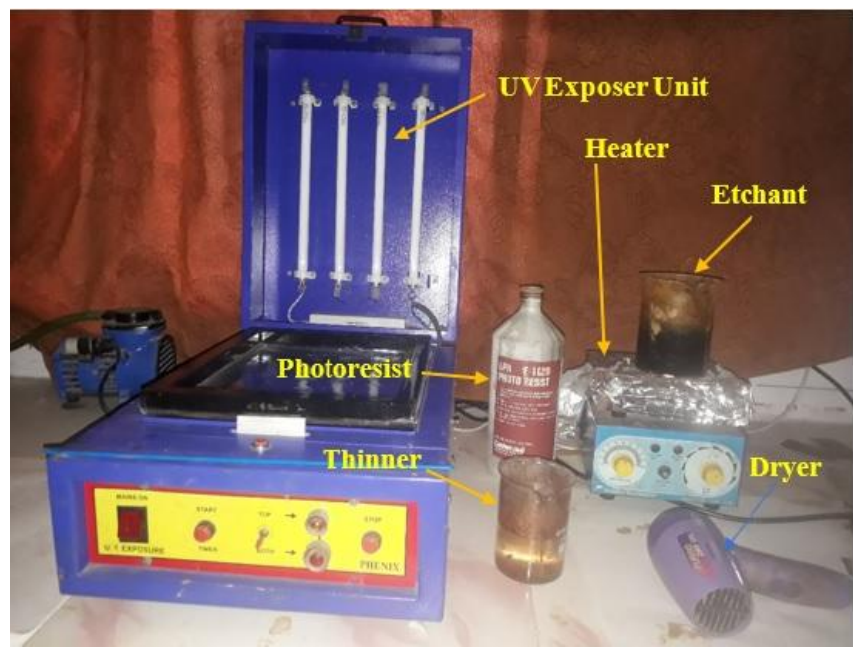

Fig.1 PCM setup

The photograph instrument drawing of chosen agreeable component is exhibited in Figure 2. The produced photograph apparatus is put on the covered example and presented to the bright source. The photoresist is touchy to the bright radiation. After U.V. presentation the example is held in the designer. This will expel the unexposed territory of the photoresist (Negative Film Method). From that point onward, the example was washed with the water and dried it. The example is kept in the etchant with persistent warming that breaks up the metal artificially. The portrayal of the procedure relies on the parameters like temperature and weakening of the etchant.

- Concentration $(\mathrm{g} / \mathrm{L})$ for 1 . Copper $=400$,

- Temperature $\left({ }^{\circ} \mathrm{C}\right)$ for 1 . Copper $=40$

Toward the end, the example was washed by utilizing water and dried. This example is then put under the RAPID I Vision 5 magnifying lens, and the different element of the example is estimated. Likewise, similarly, the components of the photograph instrument were estimated.

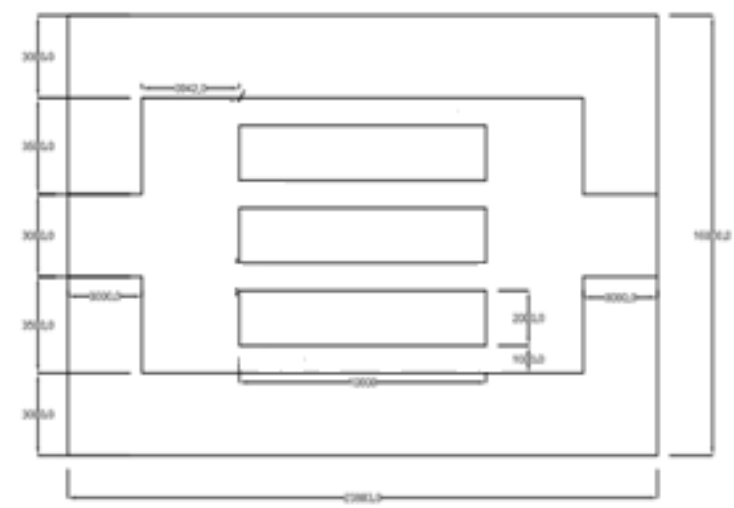

Fig.2 CAD Drawing of Photo-tool

\section{RESULT AND DISCUSSION}

To get the precise size of the example by PCM process, it needs to give some extra measurement on photograph device structure of the item. In this way, the photograph instrument estimate is kept more than the real size. There is some blunder in the ideal measurement and genuine measurement, and it is worthy. Thus, the agreeable component can be made by utilizing the PCM procedure. 


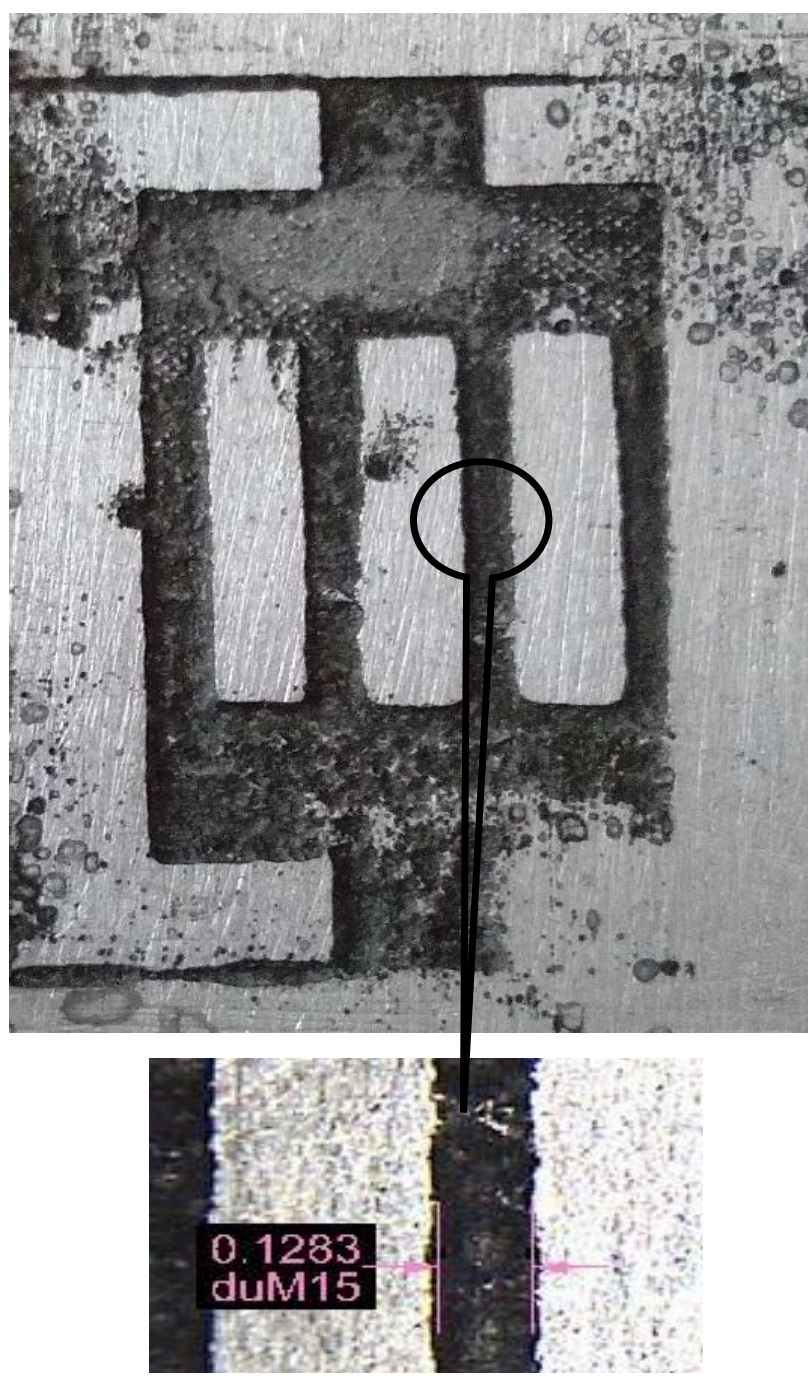

Fig. 3Fabricated Heat sink on Aluminium material

The fabricated het sink on aluminium material is shown in Figure 3. The portrayal of photograph instrument is performed utilizing RAPID I Vision 5 Microscope. The ideal width of the instrument is $1 \mathrm{~mm}$. The normal width for the photograph instrument is seen to be $1.3 \mathrm{~mm}$.

Utilizing the readied photograph apparatus, the agreeable instrument is created utilizing the PCM procedure. The created copper microchannel heat sink is appeared in Figure 4. The portrayal of the photograph device is performed utilizing RAPID I Vision 5 Microscope. The normal width of the manufactured agreeable instrument is $1.09 \mathrm{~mm}$.

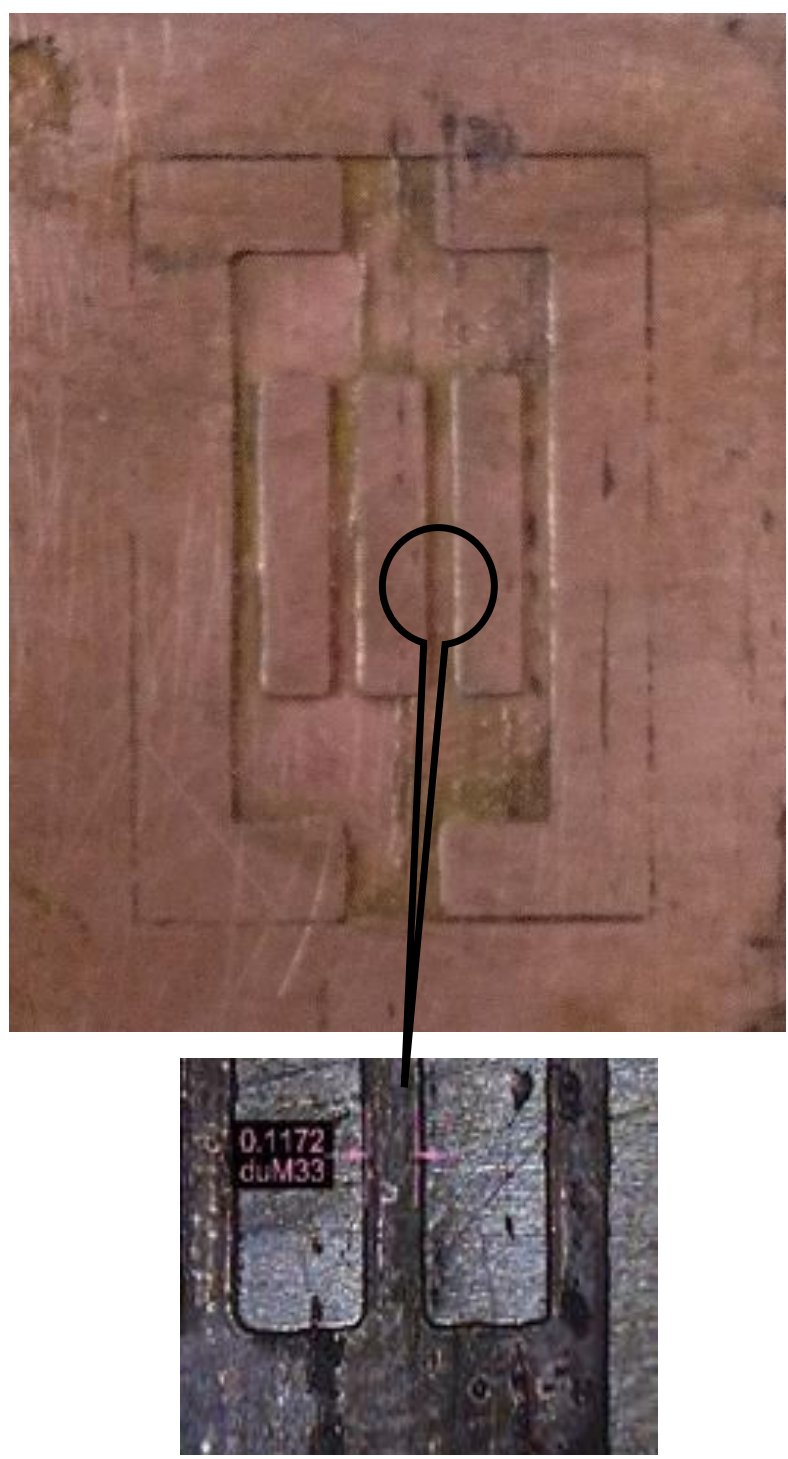

Fig. 4 Fabricated Heat sink on Aluminium material

\section{CONCLUSION}

PCM is high quality, fast turn-around economical process. In this paper, Heat Sinksare successfully fabricated by using photochemical machining on two different materials viz. copper and aluminium. The characterization of the fabricated specimens has been performed. The average width of the channels is reported as $1.3 \mathrm{~mm}$ and $1.09 \mathrm{~mm}$ for heat sink fabricated on aluminium and copper, respectively. Better surface conditions and dimensional control is achieved for copper as compared to aluminium.

\section{REFERENCES}

[1]. Chapman, A.J., 1987, "Fundamentals of Heat Transfer", Macmillan Publishing Company, p. 71.

[2]. Shah, R.K., and Bhatti, M.S., 1987, "Laminar Convective Heat Transfer in Ducts", in Kakaç, S., Shah, R.K., and Aung, W., Handbook of Single-Phase Convective Heat Transfer", John Wiley \& Sons, p. 3.42

[3]. Chen, T.S., and Armal, B. F., 1987, "Mixed Convection in External Flows", in Kakaç, S., Shah, R.K., and Aung, W., Handbook of Single-Phase Convective Heat Transfer", John Wiley \& Sons, pp 14-1 $-14-35$. 
[4]. Jadhav, S.V., Pawar, P.M. and Ronge, B.P., Effect of Pin-Fin Geometry on Microchannel Performance. Chemical Product and Process Modeling, 14(1).

[5]. Allen DM (2004) Photochemical machining: from 'manufacturing's best kept secret' to a $\$ 6$ billion per annum, rapid manufacture process. CIRP Ann-Manuf Technol 53(2):559-572. Doi : 10 1016/S0007-8506(07)60029-8

[6]. Wangikar, S. S., Patowari, P. K., \& Misra, R. D. (2017). Effect of process parameters and optimization for photochemical machining of brass and german silver. Materials and Manufacturing Processes, 32(15), 1747-1755

[7]. Yadav, R. P., \&Teli, S. N. (2014). A Review of issues in photochemical machining. International Journal of Modern Engineering Research, 4(7), 49-53.

[8]. Wangikar, S. S., Patowari, P. K., \& Misra, R. D. (2016, December). Parametric Optimization for Photochemical Machining of Copper Using Grey Relational Method. In Techno-Societal 2016, International Conference on Advanced Technologies for Societal Applications (pp. 933-943). Springer.

[9]. Wangikar, S.S., Patowari, P.K., \& Misra, R.D. (2018). Parametric Optimization for Photochemical Machining of Copper using Overall Evaluation Criteria. Materials Today Proceedings. 5(2), 4736-4742, Doi :10.1016/j. matpr.2017.12.046

[10]. Wangikar, S. S., Patowari, P. K., Misra, R. D., \&Misal, N. D. (2019), Photochemical Machining: A Less Explored Non-Conventional Machining Process. In Non-Conventional Machining in Modern Manufacturing Systems (pp. 188-201). IGI Global.

[11]. Wangikar, S. S., Patowari, P. K., \& Misra, R. D. (n.d.). Numerical and experimental investigations on the performance of a serpentine microchannel with semicircular obstacles. Microsystem Technologies.

[12]. Das, S. S., Tilekar, S. D., Wangikar, S. S., \& Patowari, P. K. (2017). Numerical and experimental study of passive fluids mixing in micro-channels of different configurations. Microsystem Technologies, 23(12), 5977-5988.

[13]. Gidde, R. R., Pawar, P. M., Ronge, B. P., Shinde, A. B., Misal, N. D. \& Wangikar, S. S (2018). Flow field analysis of a passive wavy micromixer with CSAR and ESAR elements. Microsystem Technologies, 1-14. Doi:10.1007/s00542-018-4071-3 